\title{
AVALIAÇÄO DA QUALIDADE DA ÁGUA NA \\ MICROBACIA DO CÓRREGO CAMPESTRE NO MUNICIPIO DE LINS (SP)
}

\section{WATER QUALITY EVALUATION IN \\ MICROWATERSHED OF THE CAMPESTRE STREAM \\ (LINS, SÃO PAULO STATE, BRAZIL) \\ LINS TOWN (SP)}

\section{Leandro Pereira Cuelbas ${ }^{(1)}$, Sérgio Luís de Carvalho ${ }^{(2)}$ \\ ${ }^{1,2}$ UNESP / FEIS-PPGEC, Ilha Solteira, SP, email: leandro@ctgeo.com.br, sergicar@bio.feis.unesp.br}

\section{RESUMO}

O trabalho teve como objetivo proceder à avaliação da qualidade da água na Microbacia Hidrográfica do Córrego Campestre, Município Lins, Estado de São Paulo, no período de março a dezembro de 2002, e o seu estado de degradação. Foram coletadas amostras de água em sete pontos da Microbacia e realizados ensaios de parâmetros físico-químicos e biológicos. A partir dos resultados do Índice de Qualidade de Água (IQA) e das análises de correlação e sazonalidade dos parâmetros físicos, químicos e biológicos combinados com levantamentos de campo, constatouse que as atividades antrópicas provocaram a elevação dos teores de nutrientes (fósforo e nitrogênio) e aumento dos níveis de concentrações de coliformes fecais, principalmente nos pontos de coleta que ficam dentro do perímetro urbano, onde se encontram prováveis lançamentos de esgotos clandestinos contribuindo para a degradação da microbacia estudada.

Palavras-Chave: Microbacia. Qualidade da água. Degradação ambiental. Parâmetros físico-químicos e biológicos.

\begin{abstract}
This work aims to present the water quality assessment of Campestre's Stream watershed inserted in Lins town limit, in the São Paulo' State, during the period between mars and december 2002. The water was sampled at seven points of this watershed, and then the physical, chemical and biological parameters were
\end{abstract}


analysed in the university laboratory. Through the seasonality and correlation of physical, chemical and biological parameters with the results of Water Quality Rate (WQR) and the researches on field, were possible to verify that the effects of the main antropics activities (stream channel erosion beside the complete inexistence of riparian zone) developed around these stream caused the nutrients elevation (phosphorus and nitrogen) and the increase of coliform concentration levels mainly in the urban collection points that contributed to the watershed degradation.

Keywords: Watershed. Water quality. Environmental degradation. Physic-chemical and biological parameters.

\section{INTRODUÇÃO}

\subsection{Considerações Gerais}

Nos últimos anos o uso dos recursos naturais disponíveis no mundo tem aumentado intensamente com atividades antrópicas e seus diversos modos de utilização e conseqüentemente com os recursos hídricos disponíveis nas bacias hidrográficas (TUNDISI, 2003). Os recursos naturais pertencentes às bacias hidrográficas são de extrema importância à sociedade, pois é através da utilização destes recursos que a humanidade se beneficia para sua sobrevivência. $\mathrm{O}$ mau uso dos recursos naturais tem ocorrido tanto pela escassez quanto pelo excesso de seu uso, como também pelo fato da humanidade tratar este assunto com descaso (CALIJURI e OLIVEIRA, 2000).

As bacias hidrográficas são de extrema importância à vida, pois nelas estão alguns recursos naturais, que beneficiam as comunidades com a sua utilização. Entre os vários benefícios que os recursos naturais oferecem, a água é o bem natural que todo ser vivo necessita à sua sobrevivência. É um recurso finito e a crise da água nas últimas décadas tem ameaçado a sociedade e conseqüentemente a sobrevivência de toda a biosfera. A água sempre foi um recurso estratégico à sociedade. $\mathrm{O}$ crescimento populacional e as demandas sobre os recursos hídricos superficiais e subterrâneos são algumas das causas fundamentais da crise (TUNDISI, 2003).

$\mathrm{O}$ uso inadequado dos solos, o desmatamento sem manejo e o uso indiscriminado de fertilizantes, corretivos e agrotóxicos vêm provocando inúmeros problemas ambientais, principalmente em áreas de nascentes e ribeirinhas, alterando a qualidade e quantidade de água drenada pela bacia hidrográfica (POLETO, 2003; POLETO et. al. 2004). O custo do tratamento de água para abastecimento e a recuperação de lagos, rios e represas são elevados, o que ressalta a importância da preservação e cuidados sobre as formas de utilização, tanto da própria água como também dos recursos naturais como um todo (TUNDISI, 2003).

Segundo Molina (2006) mesmo em estado de poluição, os mananciais ainda sobrevivem através de mecanismos de autodepuração. Corredeiras, meandros, quedas de água entre outras características fazem com que o manancial tende a recuperar a 
qualidade de suas águas. Anteriormente ao êxodo rural, contudo, as poluições eram geradas apenas de maneira difusa, enquanto que atualmente, com o aumento das populações urbanas, passaram a ter também caráter pontual e de alta concentração, dificultando a resposta dos corpos de água em se autodepurar.

Braga et al. (2002) relataram que os poluentes, ao atingirem os corpos de água, sofrem a ação de diversos mecanismos físicos, químicos e biológicos existentes na natureza, que alteram seu comportamento e respectivas concentrações.

Os cursos de água são os mais prejudicados com esse tipo de degradação ambiental, pois o aporte de resíduos líquidos e sólidos tanto pode influenciar negativamente na contaminação dos lençóis freáticos como nos cursos de água superficiais, prejudicando assim a vida aquática local, principalmente na região de despejo dos resíduos líquidos de esgoto tratado e não tratado.

\subsection{Qualidade da Água}

Os ecossistemas aquáticos acabam de uma forma ou de outra, servindo como reservatórios temporários ou finais de uma grande variedade e quantidade de poluentes lançados no ar, no solo ou diretamente nos corpos de água. Desta forma, a poluição do ambiente aquático, provocada pelo homem, de uma forma direta ou indireta, através da introdução de substâncias inorgânicas ou orgânicas, produz efeitos deletérios tais como: I) prejuízo aos seres vivos, II) perigo a saúde humana, III) efeitos negativos as atividades aquáticas (pesca, lazer e outras) e IV) prejuízo a qualidade da água com respeito ao uso na agricultura, indústria e outras atividades econômicas (MEYBECK e HELMER, 1992).

Segundo Meybeck e Helmer (1992), a qualidade do ambiente aquático pode ser definida: I) segundo a presença de substâncias inorgânicas ou orgânicas em diferentes concentrações e especiações e II) segundo a composição e estrutura da biota aquática presente no corpo de água. A qualidade das águas superficiais depende do clima e do solo da região, da vegetação circundante, do ecossistema aquático e da influência do homem. Sofre variações temporais e espaciais, portanto, em decorrência de processos internos e externos ao corpo de água.

Para Branco (1991), a expressão "qualidade da água" não se refere a um grau de pureza absoluto ou mesmo próximo do absoluto, mas sim a um padrão tão próximo quanto possível do "natural", isto é, tal como se encontra nas nascentes, antes do contato com o homem. Além disso, há um grau de pureza desejável, o qual depende do seu uso, que inclui abastecimento, irrigação, industrial, pesca, entre outros.

Basso (2007) afirma que a utilização de avaliações e monitoramentos contínuos é uma das medidas necessárias para a preservação dos lagos e reservatórios, os quais estão submetidos a uma pressão cada vez maior em função do desenvolvimento econômico, o que pode comprometer seriamente a qualidade dos recursos hídricos. 


\subsection{Objetivo}

O presente trabalho teve como objetivo avaliar a qualidade da água e o estado de conservação de uma microbacia da região urbana de Lins - SP, a partir da análise das condições físicas, químicas e bacteriológicas da água, utilizando-se o Índice de Qualidade da Água (IQA) como um importante parâmetro desses estudos.

\section{MATERIAL E MÉTODOS}

\subsection{Caracterização da Área de Estudo}

A área de estudo que compreende a microbacia têm influência direta sobre o Córrego Campestre e está inserida no limite do município de Lins - SP, o qual localiza-se na Região Centro Oeste do Estado de São Paulo. A região urbanizada de Lins, que será a seguir chamada de mancha urbana, possui uma área de aproximadamente $20 \mathrm{~km}^{2}$. Segundo dados do IBGE (2000), a população do município de Lins - SP foi estimada em 65.952 habitantes. A cidade de Lins possui coleta e tratamento de esgoto com cerca de $80 \%$ de coleta em lagoas de estabilização, sendo 3 lagoas anaeróbias e 3 facultativas.

\subsection{Pontos de Amostragem}

Para avaliação das condições ambientais da região pesquisada, foram escolhidos previamente 6 (seis) pontos distintos no decorrer do percurso dos córregos localizados na microbacia do Córrego Campestre. Os pontos foram denominados ponto $1,2,3,4,5$ e 6 (Figura 1), sendo que para cada um desses pontos foram registradas coordenadas geográficas por meio de aparelho GPS. 


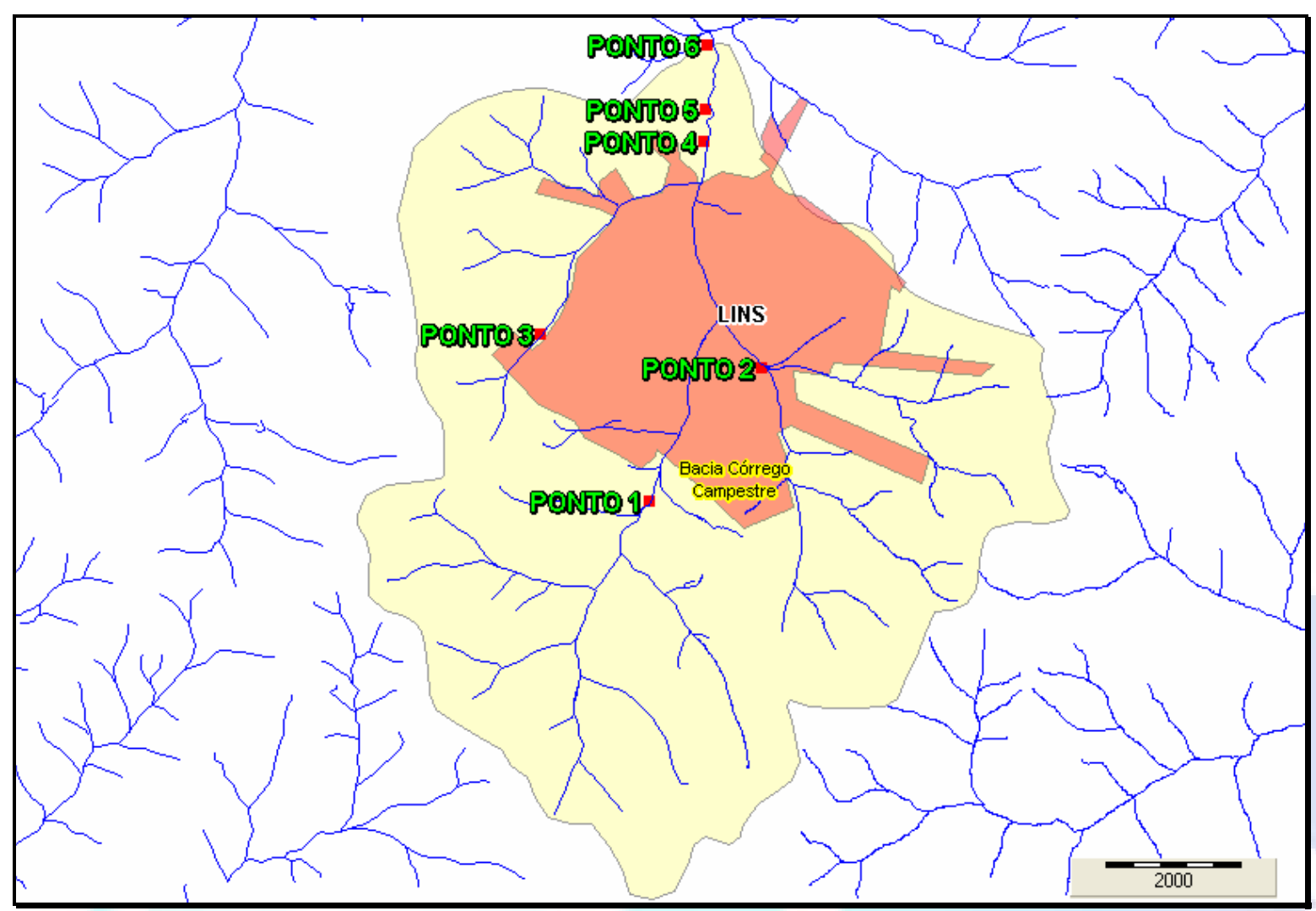

Figura 1. Imagem contendo de forma geral a localização dos 6 pontos definidos para análise da água. Fonte: Cuelbas (2007)

\subsection{Métodos Utilizados}

\subsubsection{Coleta e Análise da Água}

Para elaboração deste trabalho foi necessário o levantamento de algumas informações em campo. Foram inicialmente realizadas visitas nos locais das investigações, isto é, nos pontos onde foram efetuadas as coletas das amostras. Uma vez definidos os pontos de amostragens, foram feitas visitas nos meses préprogramados para coleta e análise da água dos cursos de água, cujas amostras foram preservadas de acordo com o Guia Técnico de Coleta de Amostras (CETESB, 2004), para a realização dos ensaios. A realização de amostragens nas sete visitas possibilitou a avaliação da dinâmica de funcionamento dos sistemas aquáticos nos períodos de seca e chuva. A quantidade coletada foi de $250 \mathrm{ml}$ em cada frasco, e a profundidade de coleta foi de 0,30 metros.

\subsubsection{Análises de Campo}

Alguns ensaios foram realizados no próprio local de amostragem, por meio de equipamentos pertencentes ao Laboratório de Análises Químicas e Controle Industrial - LACI. Sendo assim foram analisados diretamente no campo a temperatura $\left({ }^{\circ} \mathrm{C}\right)$, com equipamento analógico e o $\mathrm{pH}$ da água, com equipamento 
eletrônico digital. Dentro desse processo de coleta de informações em campo, foi ainda verificada a integridade ecológica da vegetação da microbacia, a ocorrência de fontes pontuais de contaminação da água e pontos de degradação do solo, completando dessa forma, o levantamento das condições de cada local da área de estudo.

\subsubsection{Coletas das Amostras}

Foram realizadas 7 coletas no período de 9 meses, com início no mês de abril de 2006 a dezembro de 2006, o que permitiu avaliar possíveis alterações na qualidade da água, dentro de critérios que contemplem a sazonalidade nos períodos de chuva e seca.

\subsubsection{Temperatura}

Os dados de temperatura local foram coletados por termômetro graduado a partir de $1^{\circ} \mathrm{C}$. O termômetro para coleta da temperatura local era exposto ao ar sem interferência de qualquer fenômeno natural ou artificial para preservar as condições do ambiente.

A temperatura das amostras era obtida colocando-se o termômetro dentro do frasco que continha cada amostra, imediatamente após sua coleta, retratando assim as condições ambientais do local.

\subsubsection{Preservação das Amostras das Coletas em Laboratório}

As amostras, coletadas foram armazenadas em caixas térmicas, mantendo-se assim as condições ideais para a sua preservação.

\subsubsection{Oxigênio Dissolvido (OD)}

Para a determinação laboratorial de OD $(\mathrm{mg} / \mathrm{L})$ fixou-se o oxigênio através de ensaio no próprio local da coleta. Assim sendo, as amostras destinadas ao ensaio laboratorial de OD foram coletadas em frascos de vidro, limpos e desinfetados, evitando-se movimentação ou agitação após retirá-las do curso de água, para que não houvesse alteração das condições originais. Para fixação do oxigênio foram adicionados dois reagentes, sendo eles o sulfato manganoso e a ázida sódica. Após a reação ter sido concretizada a amostra foi armazenada em caixa térmica. (APHA, 1998).

\subsubsection{Tempo e Transporte das Amostras}

O tempo de amostragem foi de aproximadamente 3 (três) horas, para coleta em todos os pontos, isto é de 1 a 6 . O transporte foi realizado por meio de automóvel com ar condicionado, visando-se preservar ao máximo as amostras coletadas. 


\subsubsection{Variáveis Analisadas}

Os parâmetros de qualidade da água foram avaliados através dos dados das análises laboratoriais com base nos Métodos para as Análises de Águas Potáveis e Residuárias - Standard Methods - $20^{\circ}$ Edição, método de espectrofotometria de absorção atômica, espectrofotometria no visível (APHA, 1998).

A escolha dos parâmetros analisados foi feita tendo como objetivo o cálculo do IQA, com base em 9 (nove) parâmetros descritos a seguir:

Parâmetros físicos: Temperatura $\left({ }^{\circ} \mathrm{C}\right)$; Sólidos suspensos totais $(\mathrm{mg} / \mathrm{L})(\mathrm{APHA}$, 1998).

Parâmetros químicos: pH, Nitrogênio Total (mg/L), Fósforo Total $(\mathrm{mg} / \mathrm{L})$, Demanda Bioquímica de Oxigênio DBO (mg/L), Oxigênio Dissolvido OD (mg/L).

Parâmetros biológicos: Coliformes Fecais e Totais (NPM/100 ml).

Os dados coletados foram tratados em planilhas eletrônicas de cálculo para geração de gráficos e figuras interessantes à avaliação da qualidade da água.

A temperatura da água $\left(\mathrm{C}^{0}\right)$ e $\mathrm{o} \mathrm{pH}$ foram analisados pelo método Eletrométrico, por meio de pHmetro de membrana.

As análises de nitrogênio total $(\mathrm{mg} / \mathrm{L})$, foram realizadas por meio de digestão ácida utilizando-se o espectrômetro de absorção atômica, onde foram determinados nitritos e nitratos organical e amoniacal formando assim o nitrogênio total (APHA, 1998).

A quantidade de OD $(\mathrm{mg} / \mathrm{L})$ foi determinada através do método de Winkler modificado, por meio de titulador (APHA, 1998).

A DBO foi determinada pelo método das diluições, incubado a $20{ }^{\circ} \mathrm{C}$ por período de 5 dias através de titulador (APHA, 1998).

A quantidade de sólidos suspensos totais $(\mathrm{mg} / \mathrm{L})$ foi determinada pelo método Gravimétrico, utilizando-se cápsula de porcelana, disco de microfibra de vidro, balança eletrônica de precisão, estufa a temperatura de $120 \quad{ }^{\circ} \mathrm{C} \quad \mathrm{e}$ dissecador/Pyrex//200mm. Idem para a fonte (APHA, 1998).

$\mathrm{Na}$ construção da fórmula paramétrica para calcular o IQA, foram estabelecidas curvas de variação da qualidade das águas de acordo com o estado ou a condição de cada um dos 09 parâmetros contemplados, assegurando um adequado grau de precisão através do uso individual ou combinado de funções lineares e não lineares segmentadas em faixas de consideração.

Para Bollmann e Marques (2000) apud Poleto (2003), a partir destas curvas de variação, sintetizadas em um conjunto de curvas médias para cada parâmetro, bem como o peso relativo aos parâmetros correspondente, é calculado o IQA, ou seja, o IQA é o produtório ponderado das qualidades de água correspondentes aos parâmetros: temperatura da amostra, $\mathrm{pH}$, oxigênio dissolvido, demanda bioquímica de oxigênio $\left(5\right.$ dias, $\left.20^{\circ} \mathrm{C}\right)$, coliformes termotolerantes, nitrogênio total, fósforo total, sólido total e turbidez. 


$$
\mathrm{IQA}=\prod_{\mathrm{i}=1}^{\mathrm{n}} \mathrm{q}_{\mathrm{i}}^{\mathrm{w}_{\mathrm{i}}}
$$

onde:

IQA : Índice de Qualidade das Águas;

qi : qualidade do i-ésimo parâmetro, um número entre 0 e 100, obtido da respectiva "curva média de variação de qualidade", em função de sua concentração ou medida e;

wi : peso correspondente ao i-ésimo parâmetro, um número entre 0 e 1 , atribuído em função da sua importância para a conformação global de qualidade, sendo que:

$$
\sum_{i=1}^{n} w_{i}=1
$$

em que:

n : número de parâmetros que entram no cálculo do IQA.

No caso de não se dispor do valor de algum dos 9 parâmetros, o cálculo do IQA é inviabilizado.

A partir do cálculo efetuado, pode-se determinar a qualidade das águas brutas indicada pelo IQA numa escala de 0 a 100 (Tabela 01).

Tabela 1 - Escala de qualidade da água indicada pelo IQA

\begin{tabular}{c|c}
\hline GRADUAÇÃO & QUALIDADE \\
\hline $79<$ IQA $\leq 100$ & qualidade ótima \\
\hline $51<I Q A \leq 79$ & qualidade boa \\
\hline $36<$ IQA $\leq \mathbf{5 1}$ & qualidade aceitável \\
\hline $19<$ IQA $\leq 36$ & qualidade ruim \\
IQA $\leq 19$ & qualidade péssima \\
\hline
\end{tabular}

Fonte: CETESB (2004)

Para verificação dos parâmetros analisados no laboratório, este trabalho toma como base de referência a Resolução do Conselho Nacional do Meio Ambiente Resolução CONAMA No 357, de 17 de março de 2005 (BRASIL, 2005). 


\section{RESULTADOS E DISCUSSÃO}

\subsection{IQA do Ponto 1}

Na Figura 2 observa-se os valores do IQA calculados para o ponto 1, cujos valores oscilaram sazonalmente, com indicativo de pior qualidade da água nos dias de chuvas, devido ao aumento nas concentrações de alguns parâmetros analisados.

Verificou-se que o ponto 1 apresentou-se com a melhor qualidade de água dentre os pontos, sendo classificada como qualidade "Boa". Essa qualidade já era esperada, devido ao seu posicionamento, pois este ponto está localizado antes da região urbanizada, sendo influenciado somente pela região rural.

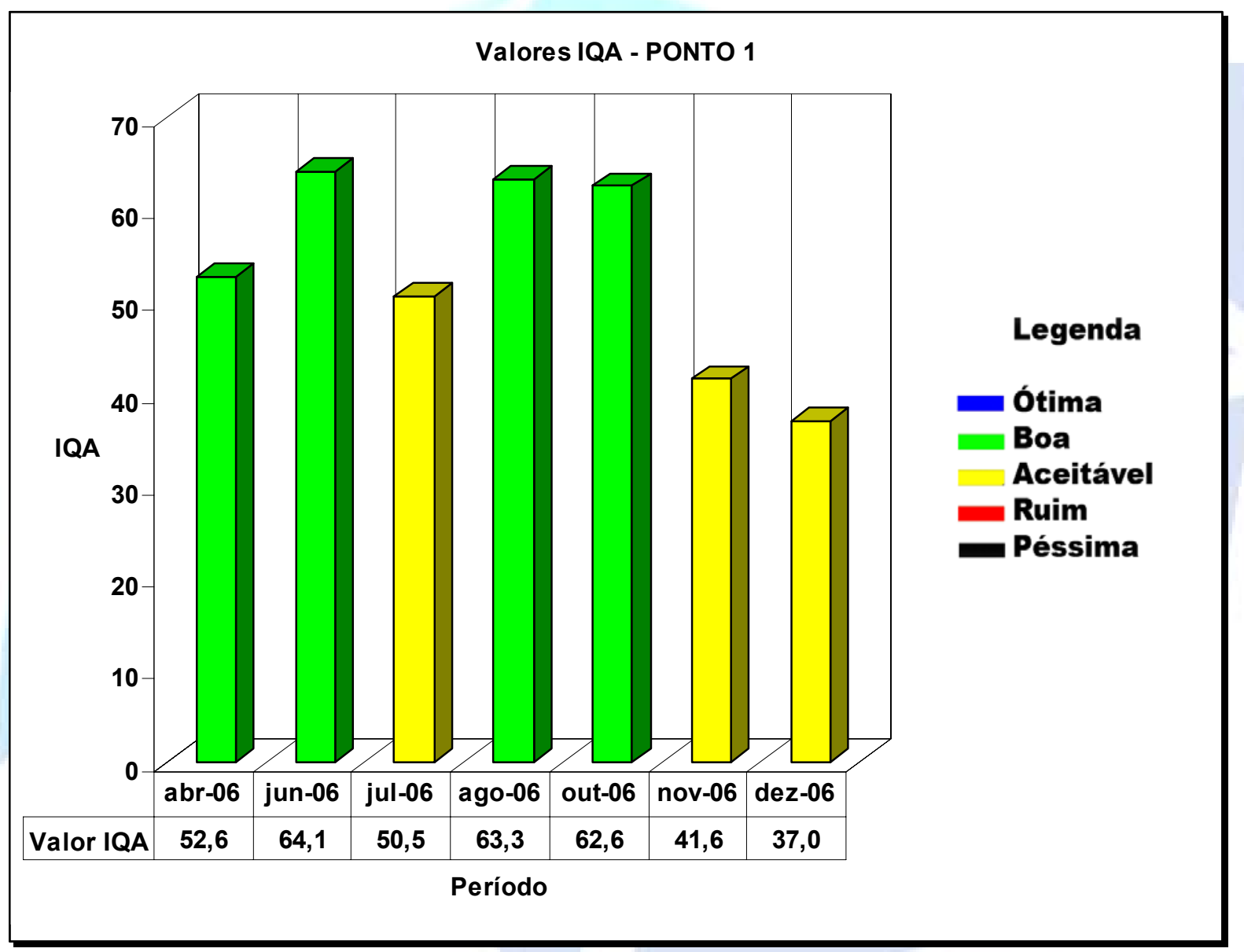

Figura 2. Valores de IQA calculados para o ponto 1 no período de abril a dezembro de 2006

\subsection{IQA do Ponto 2}

Os valores do IQA calculados para o ponto 2, oscilaram sazonalmente, com indicativo de redução da qualidade da água nos dias de chuvas, devido ao aumento nas concentrações de alguns parâmetros analisados (Figura 3), semelhantemente ao observado para o ponto 1 . Porém, no ponto 2, apenas em agosto a água se apresentou com boa qualidade. Nos meses de abril, junho, julho e outubro a qualidade foi apenas aceitável enquanto nos meses de novembro e dezembro o nível foi ruim. 
O ponto 2, teve qualidade de água, com classificação “Aceitável”, pois neste local já houve influência da área urbana. e dentre todos os pontos estudados ficou com a segunda melhor qualidade.

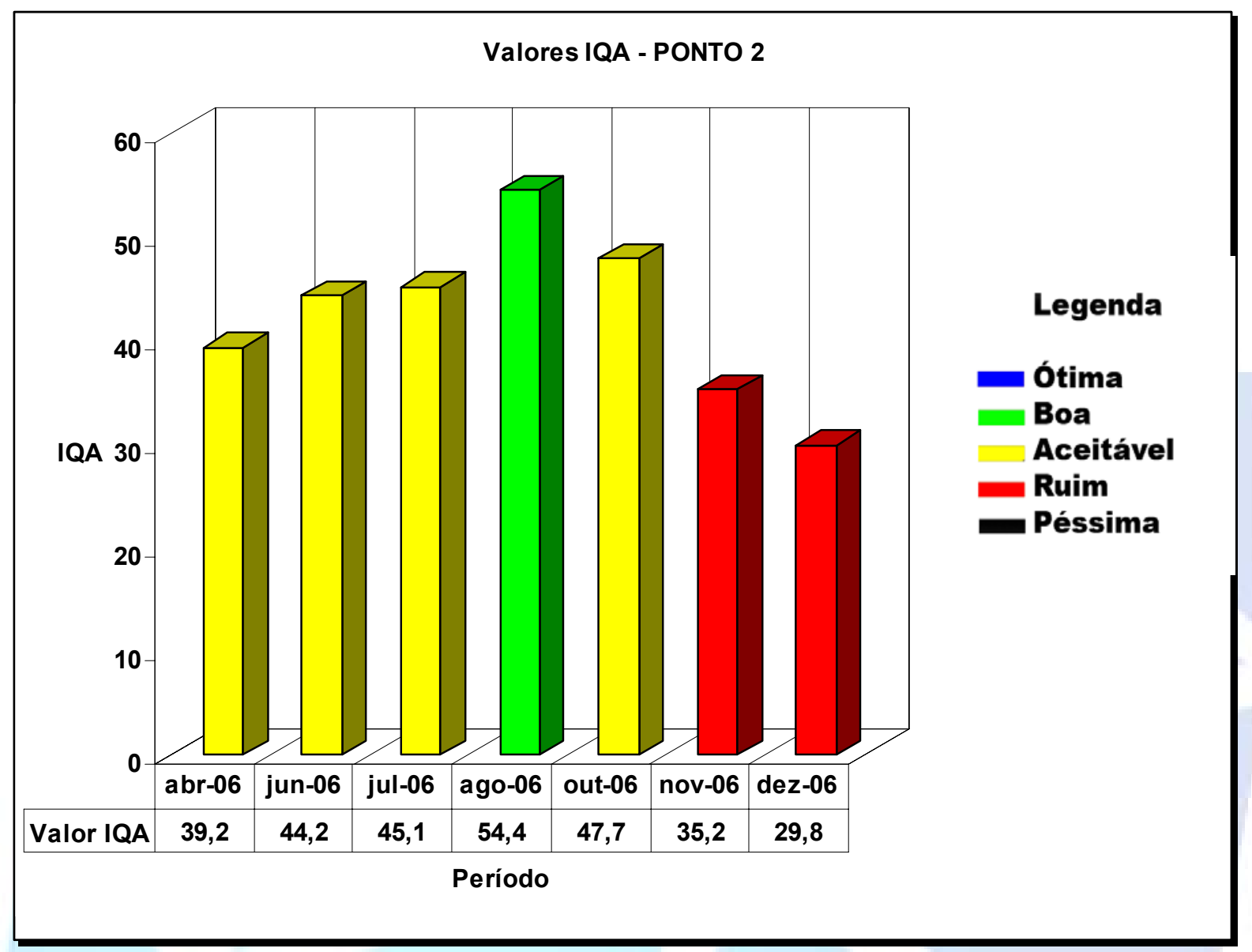

Figura 3. Valores de IQA calculados para o ponto 2 no período de abril a dezembro de 2006

\subsection{IQA do Ponto 3}

Os valores do IQA calculados para o ponto 3, oscilaram sazonalmente, mostrando menor qualidade da água no período de seca, devido ao lançamento clandestino de esgotos, onde há uma área de invasão próxima do local, havendo maior influência dos resíduos no período de estiagem que no período de chuva, devido ao aumento de volume de água neste ponto analisado, o que facilita o processo de diluição (Figura 4).

Em relação ao ponto 3, a situação é mais crítica, pois a qualidade média ficou com a classificação "Ruim". Isso ocorreu possivelmente devido à existência da indústria, próxima ao local de coleta, a qual pode estar lançando resíduos diretamente no Córrego Jacintina, visto que, a região urbana que influencia este ponto é muito pequena para as concentrações, principalmente de fósforo total, nitrogênio total, encontradas nas análises. Percebe-se que os valores, principalmente o IQA, encontrados neste ponto estão abaixo até mesmo do ponto 6 que é o situado mais a jusante no Córrego Campestre, e que sofre a influência de toda a região urbanizada, 
ficando abaixo somente do ponto 5 . O ponto 4 por sua vez, que está localizado após a passagem da água pela região urbanizada obteve, em média, classificação "Aceitável" em termos de qualidade da água.

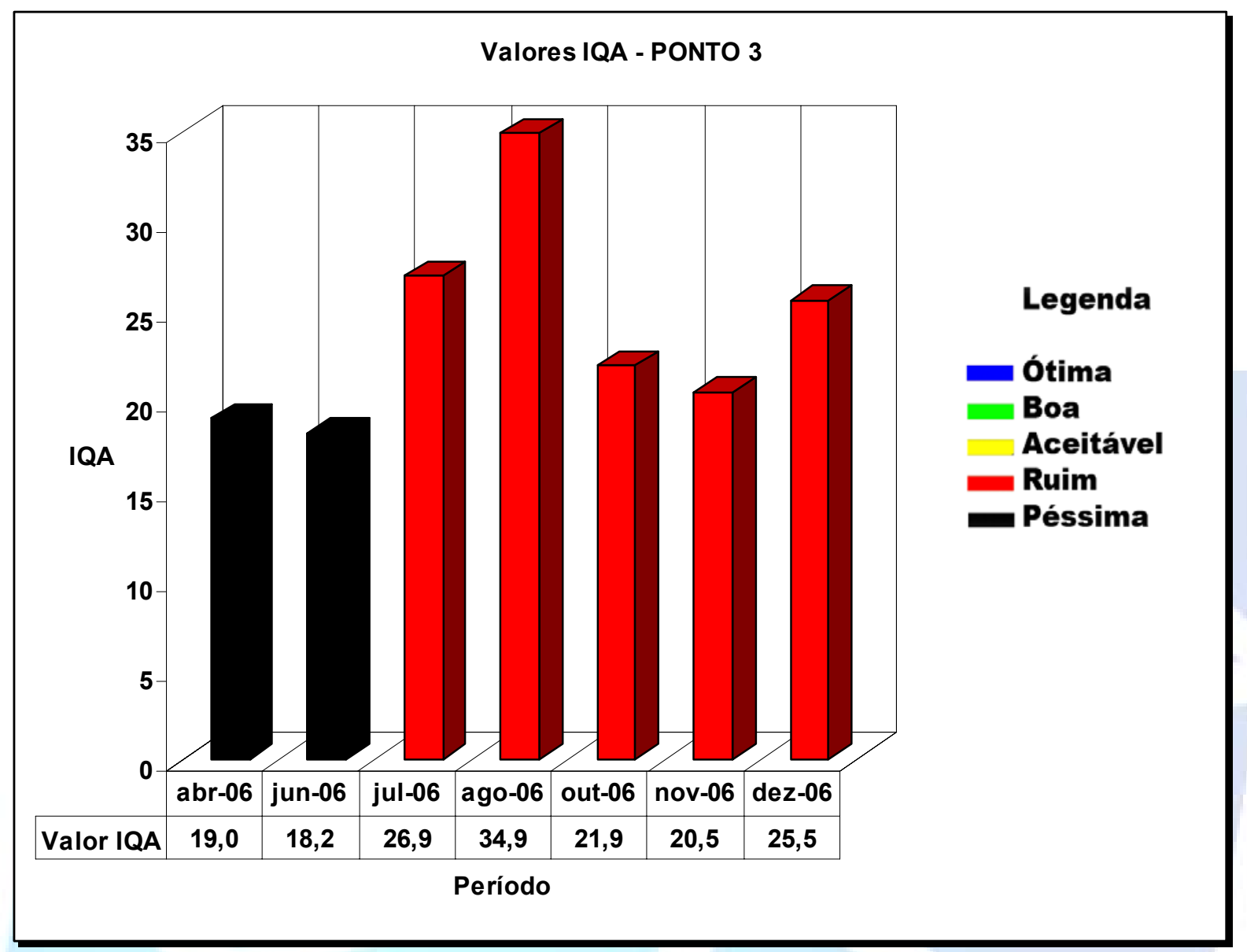

Figura 4. Valores de IQA calculados para o ponto 3 no período de abril a dezembro de 2006

\subsection{IQA do Ponto 4}

No ponto 4 os valores de IQA oscilaram sazonalmente, indicando redução da qualidade da água nos dias de chuvas, devido ao aumento nas concentrações de alguns parâmetros analisados (Figura 5), semelhantemente aos pontos 1 e 2. Apesar de todas as condições que envolvem este ponto, isto é sua localização à jusante do Córrego Campestre, Barbosa e Barbosinha e das águas terem percorrido toda a extensão da região urbanizada, o ponto 4 demonstrou uma qualidade de água superior aos pontos mais a jusantes analisados. Embora o escopo desse trabalho não seja o de análise de autodepuração, percebeu-se que houve uma melhora da qualidade da água entre o ponto 2 e 3 até o ponto 4. 


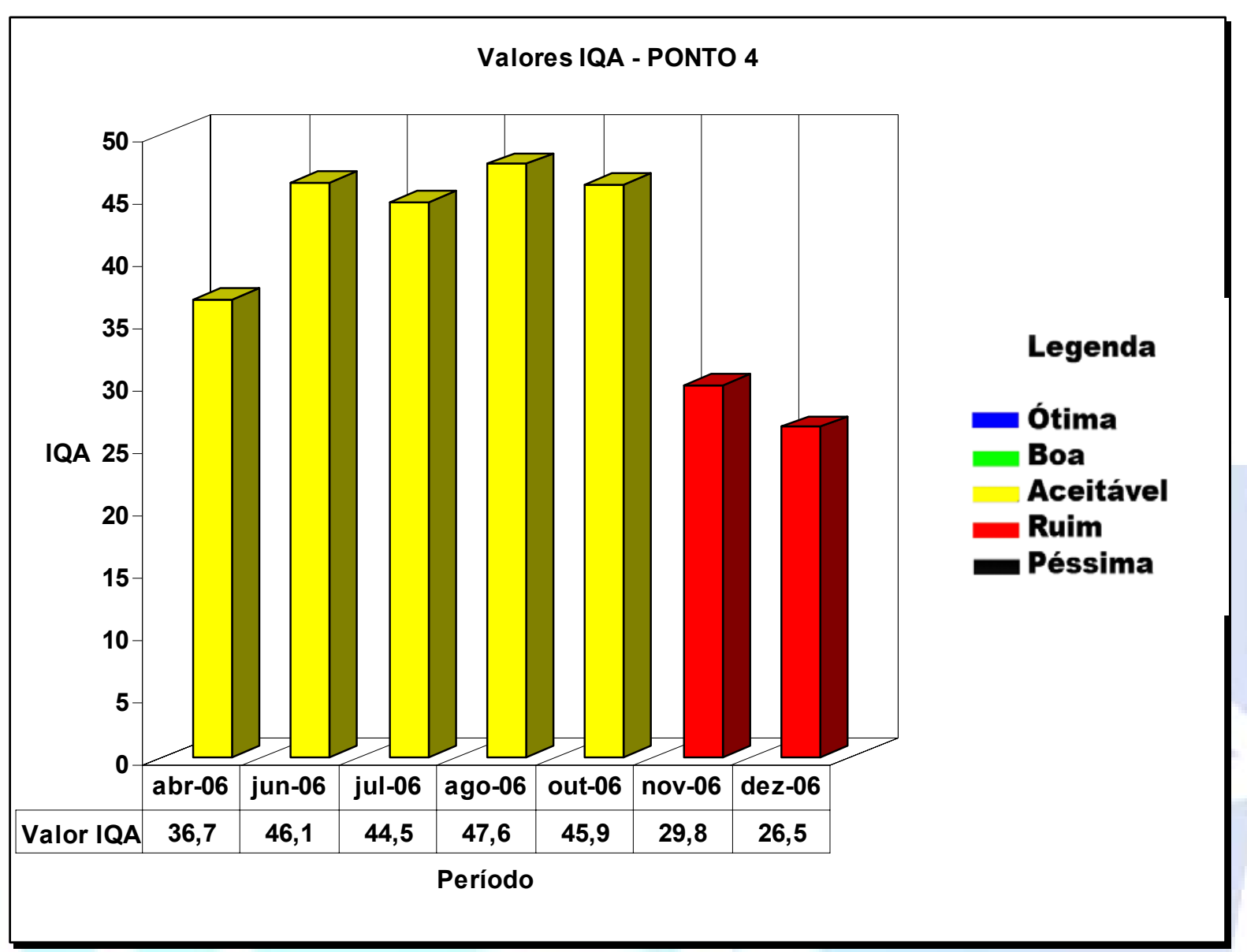

Figura 5. Valores de IQA calculados para o ponto 4 no período de abril a dezembro de 2006

\subsection{IQA do Ponto 5}

Na Figura 6 observa-se os valores do IQA calculados para o ponto 5, ocorrendo oscilação sazonal, com indicativo de pior qualidade da água nos dias de chuvas, devido ao aumento nas concentrações de alguns parâmetros analisados.

No caso do ponto 5 , assim como no ponto 3 , a situação também é crítica, pois a qualidade da água se enquadra na classificação "Péssima", tendo, em média, o pior valor de IQA dentre os pontos avaliados. Isso demonstra que a ETE e/ou o antigo lixão estão influenciando negativamente na sua qualidade. 


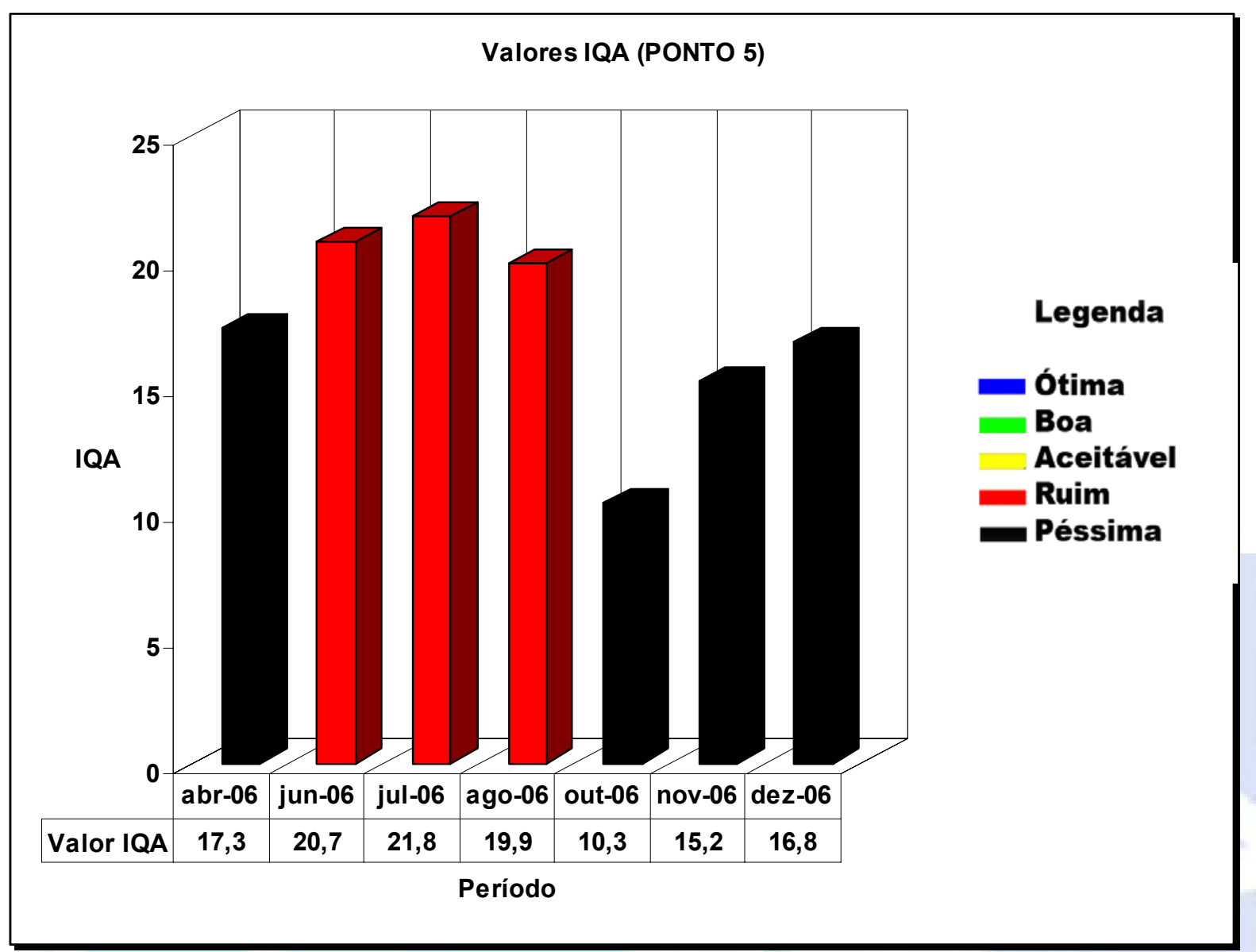

Figura 6. Valores de IQA calculados para o ponto 5 no período de abril a dezembro de 2006

\subsection{IQA do Ponto 6}

$\mathrm{Na}$ Figura 7 verifica-se os valores do IQA calculados para o ponto 6, os quais oscilaram sazonalmente indicando pior qualidade da água nos dias de chuvas, devido ao aumento nas concentrações de alguns parâmetros analisados. O ponto 6 , por ser o exutório da microbacia, sofre a influência direta dos outros pontos, que são afetados por descargas orgânicas ou inorgânicas. A qualidade de água, para esse ponto foi classificada como "Ruim", embora seu valor de IQA tenha aumentado (IQA=22,4) em relação ao ponto $5(\mathrm{IQA}=17,4)$. 


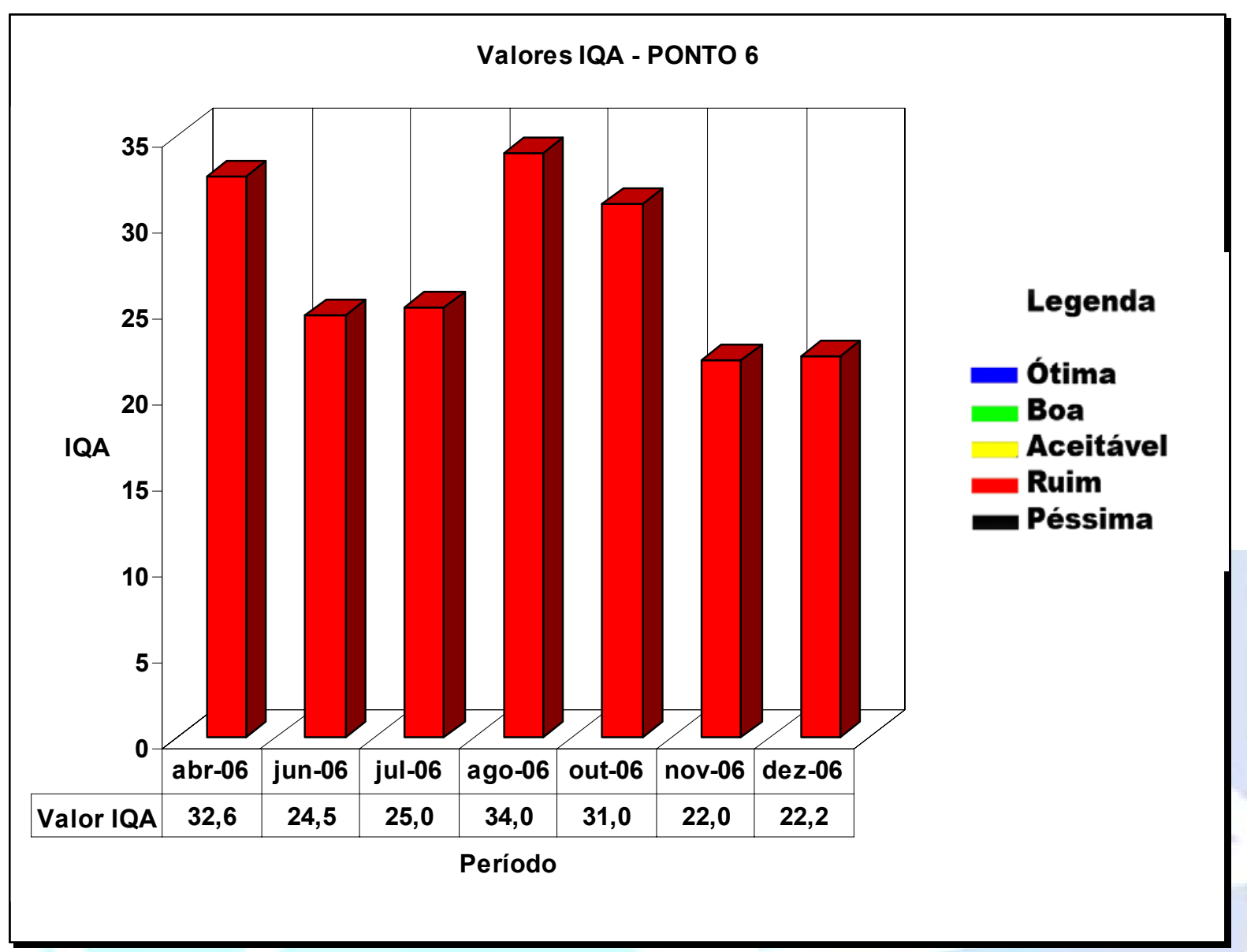

Figura 7. Valores de IQA calculados para o ponto 6 no Período de abril a dezembro de 2006

Com base nas análises laboratoriais, avaliação dos locais, imagens e resultados obtidos, procurou-se fazer uma interpretação dos principais impactos ecológicos e de riscos à saúde pública causados pela região urbanizada a microbacia, devido a sua ocupação. As concentrações dos diversos parâmetros analisados retratam os efeitos dessa poluição na microbacia em estudo. A análise dos dados coletados através das ferramentas disponíveis, demonstrou o estado de conservação/degradação da região estudada.

\section{- Índice de Qualidade da Água - IQA}

Com base na análise dos valores dos parâmetros definidos no estudo da microbacia do Córrego Campestre, foi possível constatar a sua deterioração em praticamente todo o percurso, com pontos mais degradados onde a influência antrópica é mais acentuada.

Observou-se que nos períodos de chuva, os valores na classificação da qualidade da água em todos os pontos caíram consideravelmente. Isso ocorreu provavelmente, devido a falta de mata ciliar, pois a urbanização ocupa as margens de parte do Córrego Campestre. Outro problema é a má conservação do solo ao longo dos córregos analisados, pois quando há chuva, as substâncias orgânicas e inorgânicas são levadas pelas enxurradas até os córregos, após ter passado pelo solo 
ou pelos setores de captação da região urbanizada. Conseqüentemente essas substâncias influenciaram na qualidade da água dos pontos analisados. Assim o IQA nos períodos de chuva mostrou-se mais baixo que nos períodos de seca.

\section{CONCLUSÕES}

A avaliação das condições ambientais da microbacia do Córrego Campestre, por meio da análise das características físico-químicas e bacteriológicas da água, informações do IQA, e observações sobre o uso antrópico, demonstrou que esta se apresenta, com elevado grau de degradação. Isto pode ser constatado pela alteração evidente da qualidade da água, que ocorre devido a elevada quantidade de sedimentos, coliformes e nutrientes.

È importante salientar que o processo de urbanização na região ao longo dos anos, é um dos problemas que resultou nos índices de poluição do Córrego Campestre, com acentuado comprometimento da qualidade de suas águas, decorrente de fontes pontuais e difusas de poluição, pois praticamente $25 \%$ da área de toda a microbacia do Córrego Campestre foi tomada pela região urbana.

Constatou-se também que nenhuma forma de manejo está sendo aplicada na região estudada, principalmente próximo ao ponto 5 , em que está localizado o antigo lixão, onde as águas pluviais acabam carregando resíduos para o Córrego Campestre. No caso das fontes difusas, estas podem ser observadas nos locais menos urbanizados, onde predominam chácaras com suas atividades rurais. Isto pode ser evidenciado pelos resultados do ponto 1 , o qual faz parte da região rural, onde se constatou praticamente para todos os parâmetros analisados, índices de poluição consideráveis.

É de grande importância salientar que a qualidade da água com suas características físico-químicas e bacteriológicas é essencialmente dependente das condições do próprio meio em que se encontra, sendo indicadora da situação de equilíbrio ou degradação de todo um ecossistema. Desta forma, espera-se que os resultados obtidos ao longo deste estudo, possam ter contribuído com importantes informações que possam fornecer subsídios para o desenvolvimento de novos projetos que visem um melhor conhecimento e a preservação de forma sustentável desta microbacia e dos recursos naturais desta região.

\section{REFERÊNCIAS}

BASSO, E.R.; CARVALHO, S.L. Avaliação da qualidade da água em duas represas e uma lagoa no município de Ilha Solteira - SP. Holos Environment, v.7 n.1, p.1629, 2007. 
BRAGA,B; HESPANHOL,B.; CONEJO,J.G.L.; BARROS,M.T.L.; SPENCER,M.; PORTO,M.; NUCCI,N.;JULIANO,N.; EIGER,S. Introdução à Engenharia Ambiental.1 ${ }^{a}$ Edição.São Paulo, Prentice Hall, 2002. 305p.

BRANCO, S. M. A água e o homem. In PORTO, R.L.L.; BRANCO, S.M.; CLEARY, R.W.; COIMBRA, R.M.; EIGER, S.; LUCA, S.J.; NOGUEIRA, V. D. P.Q.; PORTO, M.F. do A. Hidrologia ambiental. Editora da Universidade de São Paulo: Associação Brasileira de Recursos Hídricos. v. 3, 414 p, 1991.

BUSTOS, M. R. L. A educação ambiental sob a ótica da gestão de recursos hídricos. São Paulo, 2003. 186f. Tese (Doutorado em Engenharia Hidráulica) Escola Politécnica da Universidade de São Paulo.2003.

CALIJURI, M. C., OLIVEIRA, R. Manejo da qualidade da água: uma abordagem metodológica. In: CASTRO, R. et. al. Desenvolvimento sustentado: problemas e estratégicas. $1^{\text {a }}$ Edição. São Carlos: EESC-USP, 2000. v. 1, capitulo 1, p. 39-58.

CETESB - COMPANHIA ESTADUAL DE TECNOLOGIA DE SANEAMENTO BÁSICO. Relatório da qualidade das águas interiores do Estado de São Paulo 2003. São Paulo: CETESB, 2004. 264 p.

CLESCERI, L.S.; GREENBERG, A.D.; EATON, A.D. (Ed.) Standard methods for the examination of water and wastewater. 20.ed. Washington: American Public Health Association 1998.

CUELBAS, L. P. Monitoramento e avaliação da qualidade da água da microbacia do Córrego Campestre no município de Lins-SP. Ilha Solteira. 2007. 118f. Dissertação (Mestrado em Engenharia Civil) - Faculdade de Engenharia de Ilha Solteira, Universidade Estadual Paulista. 2007.

IBGE - INSTITUTO BRASILEIRO DE GEOGRAFIA E ESTATÍSTICA. Tabela População residente, por sexo e situação do domicílio, população residente de 10 anos ou mais de idade, total, alfabetizada e taxa de alfabetização, segundo os Municípios - 2000. http://www.ibge.com.br/cidadesat/topwindow.htm?1.

MEYBECK, M.; HELMER R. An introduction to water quality In: CHAPMAN, D. Water quality assessment. Cambridge, University Press, 1992. 585p.

MOLINA, P. M. Diagnóstico da qualidade de água na microbacia do Córrego Água da Bomba no Município de Regente Feijó - SP. Ilha Solteira, 2006.

Dissertação (Mestrado em Engenharia Civil) - UNESP. 
POLETO, C. Monitoramento e avaliação da qualidade da água de uma microbacia hidrográfica no município de Ilha Solteira - SP. Ilha Solteira. 2003. 101p. Dissertação (Mestrado em Engenharia Civil) - Faculdade de Engenharia de Ilha Solteira, Universidade Estadual Paulista.

POLETO, C; CARVALHO, S.L. Problemas de degradação ambiental em uma microbacia hidrográfica situada no município de Ilha Solteira - SP, Brasil e sua percepção pelos proprietários rurais. Holos Environment, v.4 n.1, p.68-80, 2004.

TUNDISI, J. G. Água no século XXI: enfrentando a escassez. $2^{\text {a }}$ Edição. São Paulo: Rima, 2003. 248p. 